Copyright (C) 2018 by Academic Publishing House Researcher

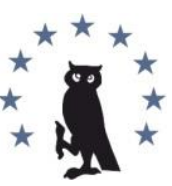

Published in the Russian Federation

European Researcher. Series A

Has been issued since 2010.

ISSN 2219-8229

E-ISSN 2224-0136

2018, 9(1): 34-41

DOI: 10.13187/er.2018.1.34

www.erjournal.ru

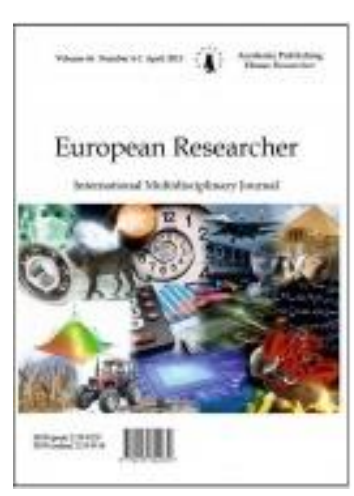

\title{
Gender Analysis of Development of Subjects of School and University in the Soviet and Russian Documentary and Television Audiovisual Media Texts
}

\author{
Elena Muryukina ${ }^{a}{ }^{*}$ \\ ${ }^{a}$ Rostov state technical university, Russian Federation
}

\begin{abstract}
The article presents the results of gender analysis of development of subjects of school and university in the Soviet and Russian documentary and television audiovisual media texts of Menheroes of the Soviet and Russian documentary and television audiovisual media texts on school and university topic have pronounced masculine characteristics: self-confidence, the desire for independence of their own attitudes, beliefs, actions, persistence, self-sufficiency. Depending on the topic of media text to meet the characters from the dominant male type to emphasized femininity. In the typology of female images N. Yakovleva highlights: hypersexual masculine, masculine, feminine, hypersexual feminine types. We found that hypersexual masculine and feminine hypersexual types do not reflect in Soviet and Russian documentary and television audiovisual media texts. The masculine type is found in the documentary films designed to promote, for example, in physical training and sports. The androgynous type widely represented in the Soviet and Russian documentary and television audiovisual media texts. in documentaries there are virtually no characters that meet the characteristics of a feminine type; the Russian television is reflected in the media texts, which are implemented at the local channels often owned by the universities.
\end{abstract}

Keywords: gender analysis, masculine, feminine signs, documentary film, TV shows.

\section{1. Введение}

Масс-медиа - один из основных факторов, влияющих на становление личности человека, понимание сущности многих явлений жизни. Так, М.Н. Володина (Язык..., 2008) утверждает, что картина мира современного человека представляет собой следующую пропорцию: 10 \% знаний опираются на собственный опыт личности и 90 \% всего, что мы знаем, приходится на медийные источники (телевидение, Интернет, кинематограф игровой и документальный, радио, фотографии и пр.).

Позиционирование гендерных образов в медиатекстах напрямую взаимосвязано с формированием системы ценностей - как социума, так и личностных смыслов отдельного индивидуума, трансформации эталонных качеств, присущих женщине или мужчине. «Процесс становления личностной идентичности всегда взаимосвязан со становлением идентичности гендерной» (Курилович, 2010: 57), поэтому актуальность приобретает интеграция факторов, способов, механизмов, обеспечивающих деятельность гендерных технологий.

\footnotetext{
${ }^{*}$ Corresponding author

E-mail addresses: murjukina@yandex.ru (E. Muryukina)
} 
Гендерные стереотипы формируются и усваиваются человеком в процессе влияния (опосредованного или непосредственного) на него разных агентов, институтов социализации. Уточняя роль каждого из данных понятий, обратимся к исследованиям С.А. Беличевой, в которых она подчеркивает, что «если социально-психологическое воздействие общества на личность происходит через средства массовой коммуникации, печать, радио, телевидение, искусство, литературу, то мы говорим об агентах социализации. Если же воздействие происходит на уровне непосредственного ближайшего окружения индивида, то мы говорим об институтах социализации» (Беличева, 1999: 74). Таким образом, очевидно, что масс-медиа относятся к агентам социализации. Последние воздействуют на личность при помощи гендерных технологий, создающих образы «гендерных стереотипов, и через показ, научение, повторение, контроль добиваются их усвоения в процессе социализации личности» (Курилович, 2010: 57).

\section{2. Материалы и методы исследования}

Основными материалами исследования стали: теоретические труды российских и зарубежных ученых (С.А. Беличевой, М. Киммела, Н.В. Курилович, Н.Б. Малаховой, О.С. Осиновской, Н. И. Яковлевой, Е.Р. Ярской-Смирновой и др.), посвященные механизмам формирования гендерных стереотипов у аудитории в процессе взаимодействия с различными институтами и агентами социализации; советские и российские документальные и телевизионные аудиовизуальные медиатексты.

К методам исследования, позволившим провести гендерный анализ, мы отнесли: теоретический, стереотипный, идентификационный, анализ характеров персонажей, а также методы синтеза, классификации, обобщения.

\section{3. Обсуждение}

Понимание значения словосочетаний «быть женщиной» или «быть мужчиной» не было статичным в разные исторические периоды, имело различное семантическое значение у рас, этносов, социальных групп. Таким образом, «если проследить развитие представлений философских школ о женственности, мужественности от античности до современных дней, то мы увидим, что философы античности и средневековья рассматривали женщину как отклонение от мужчины, от природы, а философы XIX-XX веков уже пытаются научно осмыслить, на основании чего можно делать такие выводы (3. Фрейд); провозглашается необходимость женского равноправия (Дж. Стюарт Милль, К. Маркс, Ф. Энгельс); появляется идея гармоничного взаимодополнения мужского и женского начала (русские философы Серебряного века)» (Малахова, 2013: 66).

В России после 1917 века произошло межгендерное сближение, что отразилось в образах мужчин и женщин в медиатекстах. Сокращение гендерного разрыва проявилось в активном освоении обоими полами определенных профессий, которые ранее были приоритетом только мужчин или женщин, трансформации ролей в семье (распределение семейных обязанностей), взглядов и ожиданий по отношению к образованию и работе.

Сегодня всё чаще звучит мысль о «гендерном равенстве, о том, что человек - это единое, телесно-духовное и социальное существо и, несмотря на биологические различия в структуре и химических устройствах мозга, разной физиологии, разных познавательных возможностях (память, внимание), между мужчинами и женщинами гораздо больше сходства, чем различий. И для того, чтобы люди могли жить счастливо, согласно своим желаниям, им необходимо проявлять такие качества, как любовь, нежность, забота, сострадание, компетентность, честолюбие, привязанность, самоуверенность независимо от того, мужчина это или женщина» (Киммел, 2006: 464).

Не подвергается сомнению, что масс-медиа (во всем их разнообразии) сегодня формируют культурные и социально-психологические стандарты социума, оказывают влияние на все сферы общественного менталитета, выступают в роли основного фактора приобщения личности к окружающему миру. При этом, медиатексты, включая документальные фильмы и телепередачи, выступают для своей аудитории в качестве основного транслятора гендерных стереотипов. Н.Б. Малахова отмечает различные приемы, с помощью которых происходит это воздействие: «навязывание устаревших представлений о женском и мужском предназначении; трансляция искаженного образа современных 
женщин и мужчин. Но гендерные стереотипы как социально, и культурно обусловленные мнения и оценки меняются со временем. Во многих странах, где идеи гендерного равенства получают общественную и государственную поддержку, СМИ разрабатывают новые нормы подачи информации о мужчинах и женщинах» (Малахова, 2013: 67).

Представление о реальности складывается как на уровне индивида, так и на уровне социума, коллектива. Масс-медиа сегодня стали основными производителями и трансляторами символов коллективных представлений о чем-либо, «считывание» которых обеспечивает эффективную коммуникацию личности в социуме. При этом, символ используется в медиатекстах как основной инструмент познания и отражения. Так, Э. Кассирер утверждает, что именно символ выступает «инструментом познания и конструирования действительности» (Кассирер, 1988: 29). То есть особая роль символа обусловлена спецификой процесса познания, способностью человека к абстрактному мышлению.

Н.Б. Малахова отдельное значение отводит моде, обладающей большим количеством знаков и символов, как важному компоненту гендерной технологии. С помощью моды зритель отождествляет героев с определенной социальной группой, считывает ее образцы поведения. Также мода - помогает определить половую принадлежность персонажей, «через изменения в моде можно попытаться проследить, что происходит в межполовых отношениях, с какими противоречиями сталкивается здесь общество и каков доминирующий вектор социогендерного развития. Например, в моде известен такой стиль «унисекс». Этот стиль появился в результате изменения мужской и женской роли в обществе. Главная черта этого стиля - это полное отсутствие признаков, указывающих на половую принадлежность их владельца)» (Малахова, 2013: 69).

Документальные фильмы и телевизионные передачи на протяжении всех лет своего существования активно используют символы и знаки для усиления эмоционального воздействия на зрителя, увеличения смысловой нагрузки медиатекста. Это позволяет им создавать новые мифы и реальность, в которой прослеживается и идеологическая цель. Например, в документальных фильмах «Советская семья и школа (1927-1928)», в кинолентах «Советская школа (1960 - 1969)», «Рассказывает Саша Дмитриев» (1956) с помощью символов, закадрового текста, музыки авторы демонстрировали достижения советской власти, формировали в сознании аудитории новую социалистическую реальность. При этом в советских документальных фильмах большое значение придавалось изменению статуса женщин, освоению ими новых социальных ролей, выходящих за рамки ведения домашнего хозяйства.

\section{4. Результаты исследования}

Результаты анализа мужских персонажей в отечественных документальных фильмах свидетельствуют, что их гендерная репрезентация имеет общую направленность: герои советских и российских документальных / телевизионных аудиовизуальных медиатекстов на школьную и студенческую тему в основном относятся к мужскому полу. Среди характерных качеств экранных персонажей-мужчин мы отмечаем уверенность в себе, стремление к независимости собственных взглядов, убеждений (но с обязательной аргументацией своей позиции), действий, упорство, способность к риску, самодостаточность и т.д.

Основные ценности персонажей-мужчин в документальных фильмах - ценности, опирающиеся на профессиональный опыт и личную самореализацию. В качестве примера можно привести ряд документальных лент разных лет о педагогах-новаторах: «Хозяин. Школа Сергея Чёрного» (1992), «Вальдорфская школа» (1992), «Интервью директора школы «Класс-центр» С.З. Казарновского» (1991), «Школа на Брянской» (1994), «Ищу учителя» (2014) и др.

Экранная репрезентация педагогов-мужчин включает в себя демонстрацию их творческого понимания целей и содержания педагогического процесса, предприимчивости, организаторских способностей, умения повести за собой как коллектив единомышленниковучителей, родителей, так и детей школьного возраста. Стиль одежды этих педагогов зачастую выходит за рамки «офисного» шаблона. Так, директор школы С.З. Казарновский, одетый в свитер и джинсы, во время интервью сидит на диване в своем кабинете в свободной 
позе. Рассказ о собственном педагогическом опыте С.Г. Черный ведет на природе, он сидит на траве в одежде вольного стиля. Его монолог представляет собой четкую структуру, состоящую из трех основных компонентов: прошлое, настоящее и будущее. Набор перечисленных нами и многих других кодов и знаков направлен на создание у зрителя образа героя как мужчины, профессионала, обладателя лучших маскулинных качеств.

При анализе мы опирались на понятие «фейсизм» (Ш. Берн). Мы можем утверждать, что согласно ему, в советских и российских документальных и телевизионных аудиовизуальных медиатекстах зачастую женские и мужские образы педагогов представлены непропорционально реальному положению дел. Во-первых, в реальной жизни учителей-женщин намного больше, чем мужчин, а на экранные имиджи документального кино отдаются в значительной степени именно мужчинам. Во-вторых, в документальном кино учителя-мужчины презентуются как интеллектуалы, камера фиксирует их лицо, мимику, в то время как у учителей-женщин на первый план в визуальном ряде чаще выходит фигура.

Учащиеся школьного возраста нередко предстают в документальных и телевизионных медиатекстах в едином дресс-коде: пионерской форме, гимназической форме и пр. Например, конкурсные условия, поведение ведущего по отношению к участникам в телепередаче «Умники и умницы» подчеркивает равенство полов; соревнующиеся одеты очень строго, отсутствуют любые акценты сексуальности (это проявляется, в частности, в том, что не допускаются распущенные волосы или эффектные укладки у девушек). Участницы конкурса учебных знаний в области гуманитарных наук представлены как сильные личности, ничем не уступающие «сильному» полу, которые готовы вести с ним равную борьбу.

Основополагающие ценности для анализируемых персонажей - общественное признание и активная, результативная профессиональная деятельность. Часто в таких медиатекстах мы встречаемся с построением основной сюжетной линии на преодолении трудностей, которые возникли перед персонажем. В качестве таковых выступают реформирование образования, введение новых стандартов, новые экономические условия (в перестроечный или «ельцинский» период), гуманистическая парадигма развития педагогики и пр.

Женские гендерные образы представлены в документальных фильмах на тему школы и вуза более вариативно. В зависимости от тематики медиатекста можно встретить персонажей от преобладающего мужского типа до подчеркнутой женственности. В своей работе мы хотим обратиться к типологии женских образов, представленной в работе Н.И. Яковлевой. В ней выделяются: маскулинный гиперсексуальный тип, маскулинный тип, феминный тип, андрогинный тип, феминный гиперсексуальный тип.

Рассмотрим характеристики и отражение каждого из заявленных типов в советских и российских документальных и телевизионных аудиовизуальных медиатекстах на тему школы и вуза.

Маскулинный гиперсексуальный тип. Н.И. Яковлева дает следующую характеристику представителям данного типа в медиатекстах: «героини обладают маскулинными чертами, наравне с мужчинами выполняют социально значимые роли. Сексуальность, выраженная в первую очередь с помощью атрибутивной поддержки, выступает одним из немногих феминных признаков, который, однако, стереотипизирует женщину» (Яковлева, 2009: 485). Согласно результатам нашего анализа советских и российских документальных и телевизионных аудиовизуальных медиатекстов на школьную и студенческую тематику, данный тип не находит в них отражения.

Маскулинный тип: «Героини обладают маскулинными чертами, а также наравне с мужчинами выполняют социально значимые роли. Акцент не делается на сексуальной атрибутике. Женщины представлены, как сильные личности, выполняющие важное предназначение, однако в локальной сфере» (Яковлева, 2009: 485). Наш анализ советских и российских аудиовизуальных медиатекстов школьно-студенческой тематики показал, что данный тип встречается в отечественных документальных фильмах. Например, маскулинный тип девочки, девушки, женщины, встречается в документальных картинах, призванных популяризировать занятия физкультурой, стимулировать занятия спортом: 
«Знакомьтесь: народная гребля. Этот необычный обычный урок. Современные Икары» (1982), «Подари себе радость» (1990) и др.

Другим видом документальных фильмов, где находит отражение в персонажах маскулинный тип женщины, можно считать некоторые медиатексты профориентологической направленности: «Я б в строители пошел...» (1980); «Серебряные крылья» (1973) и пр. В этом контексте нельзя обойти вниманием и документальные фильмы, где раскрывались и пропагандировались различные виды вовлечения студентов в трудовую деятельность (стройотряды, трудовые семестры, поездки на целину, комсомольские стройки): «Студенческие строительные» (1973), «Третий трудовой» (1978) и др.

Андрогинный тип: «Женщины обладают качествами, традиционно отожествляемые с мужчинами, наравне с мужчинами выполняют социально значимые роли. Однако, для них также характерны и феминные качества, связанные в первую очередь со способностью выслушать, поддержать, при необходимости утешить. В данном случае мы не говорим о навязанной сексуальности, так как выражена она довольно слабо, и намеренно не выставляется напоказ» (Яковлева, 2009: 485). Данный тип широко представлен в советских и российских документальных и телевизионных аудиовизуальных медиатекстах. Например, в документалистике андрогинный тип часто встречается в героинях - учителях, директорах, ведущих инновационную деятельность, организовавших свою работу на принципах гуманизма.

В представленной нами типологии документальных фильмов (Мурюкина, 2017) такие персонажи встречаются в медиатекстах:

- освещающих проблемы детей в школе (появилась в середине 1980-х годов, когда стало возможным говорить не только о достижениях, но и сложностях, возникающих в образовании школьников: «Самые младшие школьники» (1985), «Школа: прогноз на завтра» (1989), «Идём по кругу? Не останавливаемся?» (1990) и др.;

- раскрывающих инновационную деятельность, авторские разработки педагогов: «Активизация обучения (из опыта работы школ Татарии)» (1975), «Дважды два» (1987), «Школа. Взгляд с надеждой» (1989) и др.

Героини (как взрослые, так и школьницы, студентки) в документальных медиатекстах выполняют социально значимую роль. Одежда героинь опрятная, но не вычурная, поскольку необходимый акцент должен приходиться на ее деятельность, профессиональные качества, квалификацию, а не на восприятие (в первую очередь) как женщины. В фильмах подчеркивается ее гендерная принадлежность через «женские» качества - способность выслушать, найти слова поддержки. В данном случае мы не говорим о навязанной сексуальности, так как выражена она довольно слабо и намеренно не выставляется напоказ.

Андрогинный тип находит отражение и в телепередачах советского и российского производства на школьную и студенческую тему. Например, у персонажей телепередачи «АБВГДейка» гендерная принадлежность выражается в одежде, диалогах, чертах характера, которыми обладают герои: Макаронка - добрая, отзывчивая, эмпатийная; учительница Татьяна Кирилловна или (в настоящее время) Кристина Алексеевна - рассудительная, справедливая, терпеливая; Санёк и Печкин - иногда самоуверенные, бескомпромиссные, задиристые. Одежда и поведение персонажей «АБВГДейки» транслируют целевой аудитории основные гендерные признаки, характеристики, способствуя формированию их собственной гендерной принадлежности.

Современное телевидение представлено новым видами телепередач (ток-шоу, журналистские расследования и пр.) школьной и студенческой тематики, где поднимаются проблемы образования в школе и вузе в России. Героини - представители науки, образования, министерские работники и др. демонстрируют на экране профессионализм в обсуждаемой теме, собственное мнение о проблеме, умение его аргументировать, вступать в диалог с представителями противоположного пола. Но для них характерна и демонстрация феминных качеств, что проявляется в одежде (прежде всего, это подчеркивает классический стиль), такте по отношению к собеседникам, способность слушать и пр.

Феминный тип: «Женщины, обладающие, преимущественно феминными качествами. Акцент не делается на выполнении социально значимых ролей. Чаще всего представлены, как творческие личности, желающие реализации в определённой локальной сфере, не требующей широкого общественного признания» (Яковлева, 2009: 485-486). 
Изучение и анализ советских и российских документальных и телевизионных аудиовизуальных медиатекстов с точки зрения героев, обладающих феминным типом, позволил нам прийти к следующим выводам:

- в отечественных документальных фильмах мы практически не встречаем персонажей, по своим характеристикам отвечающих феминному типу. Это обусловлено установкой коммунистической партии, согласно которой деятельность каждого человека должна быть социальна значима и полезна обществу. Так, в документальном фильме «Сюжеты. Советская семья и школа» (1927 - 1928) авторы как бы проживают один день из жизни девочки - ученицы младших классов. Мы видим кадры ее учебы в школе; встречи с отцом после окончания смены на заводе; совместного прихода домой, где их встречает мать героини. Затем дочь уводит отца в комнату, дает ему листок бумаги с текстом, который он начинает читать. В это же время мать девочки идет на кухню, ставит чайник на плиту. То есть в документальном фильме мы встречаем представителя феминного типа в лице мамы ученицы: она не выполняет социально значимой роли и, занимаясь ведением домашнего хозяйства, не стремится выйти за ее рамки. Но авторами подчеркивается с помощью монтажа, что девочка предпочитает помощи маме общение с папой, поскольку он умеет читать, может помочь ей подготовить уроки и т.д. То есть феминный тип персонажей противоречил складывающейся идеологии, согласно которой все граждане СССР должны быть социально активны;

- в российских телепередачах на студенческую тему можно встретить представителей феминного типа. К примеру, на локальных, местных каналах (в районе города, области), чаще всего, университетских, ведущими телепередач часто становятся девушки-студентки, которые обладают указанными характеристиками. Они демонстрируют ярко выраженные феминные качества, что позволяет привлечь внимание аудитории к информации, сделать ее аттрактивной. Ведущие презентуют зрителям свои креативные способности, что находит отражение, в том числе, в умении одеваться, делать макияж, прическу. Для университетского телевидения это важный аспект, поскольку, в съемочной группе нет визажистов, стилистов и пр.

Для феминного типа героинь большое значение имеет внешний вид, трендовая одежда, поскольку она несет в себе большое количество знаков и символов: демонстрирует принадлежность к социальному слою; усиливает привлекательность и пр. Наш анализ показал, что героини феминного типа в телепередачах на студенческую тему не используют в одежде такой стиль как «унисекс», напротив, их одежда подчеркивает женственность, формы обладательницы.

Феминный гиперсексуальный тип: «Женщины, обладающие преимущественно феминными качествами, которые также подчеркиваются ярко выраженной сексуальностью. Им не приписываются социально значимые роли во внешней сфере. Таким героиням чаще всего не отводятся главные роли в сюжете. Они зачастую появляются рядом с мужчиной, которого «дополняют» тем, или иным образом» (Яковлева, 2009: 486). Этот тип в анализируемых нами советских и российских документальных и телевизионных аудиовизуальных медиатекстах на школьную и студенческую тему не находит отражения, хотя в игровом кинематографе российского периода, он напротив, часто акцентируется («Физика или химия», «Барвиха», «Филфак» и пр.)

\section{5. Выводы}

Итак, мужские персонажи советских и российских документальных и телевизионных аудиовизуальных медиатекстов на школьную и студенческую тему имеют ярко выраженные маскулинные признаки: уверенность в себе, стремление к независимости собственных взглядов, убеждений, действий, упорство, самодостаточность. В зависимости от тематики медиатекста можно встретить персонажей от преобладающего мужского типа до подчеркнутой женственности.

Маскулинный гиперсексуальный и феминный гиперсексуальный типы в советских и российских документальных и телевизионных аудиовизуальных медиатекстах практически не находят отражения. Маскулинный тип встречается в документальных фильмах, например, призванных популяризировать занятия физкультурой и спортом. Андрогинный тип широко представлен в советских и российских документальных и телевизионных 
аудиовизуальных медиатекстах. В документалистике он часто встречается у героинь учителей, директоров, осуществляющих инновационную деятельность, опирающуюся на принципы гуманизма. В отечественных документальных фильмах о школе и вузе почти нет персонажей, отвечающих характеристикам феминного типа; в российских телепередачах этот тип находит отражение в медиатекстах, реализующихся на локальных, местных каналах, часто принадлежащих университетам.

\section{6. Благодарности}

Статья написана в рамках исследования при финансовой поддержке гранта Российского научного фонда (РНФ). Проект № 17-18-01001 «Школа и вуз в зеркале советских, российских и западных аудиовизуальных медиатекстов», выполняемый в Ростовском государственном экономическом университете.

\section{Литература}

Беличева, 1994 - Беличева C.A. Основы превентивной психологии. М.: Соц. здоровье России, 1994. 199 с.

Кассирер, 1988 - Кассирер Э. Опыт о человеке: Введение в философию человеческой культуры. Проблема человека в западной философии. М.: Прогресс, 1988. 552 с.

Киммел, 2006 - Киммел M. Гендерное общество. М.: Российская политическая энциклопедия, 2006. 464 с.

Курилович, 2010 - Курилович, Н.В. Гендерный анализ средств массовой информации: методологический аспект. Минск: Право и экономика, 2010. 169 с.

Малахова, 2013 - Малахова Н.Б. Гендерные технологии как средство формирования гендерной идентичности в современных условиях // Известия МГТУ «МАМИ», № 1 (15). 2013, т. 6. С. 66-70.

Мурюкина, 2017 - Мурюкина E.B. Герменевтический анализ советских документальных фильмов и телепередач на школьную и студенческую тему // Медиаобразование. 2017. № 3. С. 118-133.

Язык, 2008 - Язык средств массовой информации / Под ред. М.Н. Володиной. М.: Академический Проект; Альма Матер, 2008. 760 с.

Яковлева, 2009 - Яковлева Н.И. Роль кино в формировании гендерных репрезентаций. 2009. URL: http://elib.bsu.by/bitstream/123456789/150841/1/484-487.pdf. Дата доступа 1.10.2017.

Ярская-Смирнова, 2001 - Ярская-Смирнова E.P. Гендер, власть и кинематограф: основные направления феминистской кинокритики // Журнал социологии и социальной антропологии. 2001. T. IV. № 2. С. 100-118.

\section{References}

Belicheva, 1994 - Belicheva S.A. (1994). Osnovy preventivnoi psikhologii [Fundamentals of preventive psychology]. M.: Sots. zdorov'e Rossii, 199 p.

Cassirer, 1988 - Kassirer E. (1988). Opyt o cheloveke: Vvedenie v filosofiyu chelovecheskoi kul'tury [An essay on man: an Introduction to philosophy of human culture]. Problema cheloveka v zapadnoi filosofii. M.: Progress, $552 \mathrm{p}$.

Kimmel, 2006- Kimmel M. (2006). Gendernoe obshchestvo [Gender relations]. M.: Rossiiskaya politicheskaya entsiklopediya, $464 \mathrm{p}$.

Kurilovich, 2010 - Kurilovich, N.I. (2010). Gendernyi analiz sredstv massovoi informatsii: metodologicheskii aspect [Gender analysis of the media: methodological aspect]. Minsk: Pravo i ekonomika, $169 \mathrm{p}$.

Malakhova, 2013 - Malakhova, N.B. (2013). Gendernye tekhnologii kak sredstvo formirovaniya gendernoi identichnosti v sovremennykh usloviyakh [Gender technologies as means of formation of gender identity in modern terms]. Izvestiya MGTU «MAMI», № 1 (15). t. 6. pp. 66-70.

Murjukina, 2017 - Murjukina, E.V. (2017). Germenevticheskii analiz sovetskikh dokumental'nykh fil'mov i teleperedach na shkol'nuyu i studencheskuyu temu [Hermeneutic analysis of Soviet documentary films and television programs on school and student theme]. Mediaobrazovanie. № 3. pp. 118-133. 
Yazyk, 2008 - Yazyk sredstv massovoi informatsii [The language of the media]. Pod red. M.N. Volodinoi. M.: Akademicheskii Proekt; Al'ma Mater, 2008. 760 p.

Yakovleva, 2009 - Yakovleva, N.A. (2009). Rol' kino v formirovanii gendernykh reprezentatsii [The role of cinema in shaping gender representations]. URL: http://elib.bsu.by/bitstream/123456789/150841/1/484-487.pdf. Data dostupa 1.10.2017.

Yarskaya-Smirnova, 2001 - Yarskaya-Smirnova, E.R. (2001). Gender, vlast' i kinematograf: osnovnye napravleniya feministskoi kinokritiki [Gender, power and cinema: the main directions of feminist film critics]. Zhurnal sotsiologii i sotsial'noi antropologii. T. IV. № 2. pp. 100-118.

\title{
Гендерный анализ развития тематики школы и вуза в советских и российских документальных и телевизионных аудиовизуальных медиатекстах
}

\author{
Елена Мурюкина а ,*
}

а Донской государственный технический университет, Российская Федерация

Аннотация. В статье представлены результаты гендерного анализа развития тематики школы и вуза в советских и российских документальных и телевизионных аудиовизуальных медиатекстах Мужчины-герои советских и российских документальных и телевизионных аудиовизуальных медиатекстов на школьную и студенческую тему имеют ярко выраженные маскулинные признаки: уверенность в себе, стремление к независимости собственных взглядов, убеждений, действий, упорство, самодостаточность. В зависимости от тематики медиатекста можно встретить персонажей от преобладающего мужского типа до подчеркнутой женственности. В типологии женских образов Н.И. Яковлева выделяет: маскулинный гиперсексуальный, маскулинный, феминный, феминный гиперсексуальный типы. Мы выявили, что маскулинный гиперсексуальный и феминный гиперсексуальный типы в советских и российских документальных и телевизионных аудиовизуальных медиатекстах не находят отражения. Маскулинный тип встречается в документальных фильмах: призванных популяризировать занятия физкультурой и спортом; профориентологической и пропагандистской направленности. Андрогинный тип широко представлен в советских и российских документальных и телевизионных аудиовизуальных медиатекстах. В документалистике он часто встречается у героинь - учителей, директоров, осуществляющих инновационную деятельность, опирающуюся на принципы гуманизма. Изучение и анализ советских и российских документальных и телевизионных аудиовизуальных медиатекстов с точки зрения героев, обладающих феминным типом, позволил говорить о следующем: в документальных фильмах практически не встречаются персонажи, отвечающие характеристикам феминного типа; в российских телепередачах находит отражение в медиатекстах, реализующихся на локальных, местных каналах, часто принадлежащих университетам.

Ключевые слова: гендерный анализ, маскулинные, феминные признаки, документальные фильмы, телепередачи, студенты, школьники.

\footnotetext{
${ }^{*}$ Корреспондирующий автор

Адреса электронной почты: murjukina@yandex.ru (Е. Мурюкина)
} 